\title{
Reaction of active methylene compounds with 4-fluorobenzalanilines and antifungal potential of the products
}

\author{
Randeep Kaur Sandhar ${ }^{a}$, J. R. Sharma ${ }^{b}$ and M. R. Manrao ${ }^{a *}$ \\ ${ }^{a}$ Department of Biochemistry and Chemistry, ${ }^{b}$ Department of Plant Pathology, Punjab Agricultural University, \\ Ludhiana-141 004, Punjab, India
}

Manuscript received 30 December 2004, revised 7 October 2005, accepted 10 November 2005

\begin{abstract}
Condensation of active methylene compounds (1-6) with 4-fluorobenzalaniline resulted in the formation of addition-elimination products $1 \mathrm{a}-6 \mathrm{6}$ respectively. The products were identified on the basis of elemental analysis, m.m.p. determination and spectral studies and were screened in vitro for their antifungal potential against four phytopathogenic fungi.
\end{abstract}

Keywords : Methylene compounds, antifungal agents.

In continuation of our work on substitution on benzalaniline and biological activity of the products, in this paper we have presented our study on the effect of fluoro substituent in the para position of C-phenyl ring of benzalanilines on the course of the condensation of active methylene compounds and to evaluate the products for their antifungal potential ${ }^{l}$.

The reaction of cyanoacetic acid with 4-fluorobenzalaniline yielded a crude product which was recrystallized from ethanol. The product was identified as 4fluorobenzalcyanoacetic acid (1a) with support of elemental analysis, IR and PMR studies. The infrared spectrum of the compound showed absorption bands at 2235 and $1710 \mathrm{~cm}^{-1}$ indicating the presence of cyano group and carboxylic carbonyl respectively. The absorption at 1590 and $870 \mathrm{~cm}^{-1}$ showed the presence of $-\mathrm{CH}=\mathrm{C}<$ linkage. The five proton multiplet between $\delta$ 7.0-8.4 in the PMR spectrum of $1 \mathrm{a}$ in $\mathrm{CDCl}_{3}$ accounted for four aromatic protons and one olefinic proton in la. Determination of m.m.p. (no depression) with an authentic sample of the compound prepared by alternative route further confirmed the structure of la. The result of this reaction is at variance as compared to the reaction of cyanoacetic acid with benzalaniline where addition product has been reported ${ }^{1}$.

Condensation of malononitrile with 4-fluorobenzalaniline gave a crude solid which was recrystallized from methanol. The pure solid thus obtained was identified an addition-elimination product viz. 4fluorobenzalmalononitrile (2a) on the basis of elemental analysis, m.m.p. determination (no depression) with authentic sample and IR studies. The infrared spectrum of the compound showed absorption at 2230, 1585 and 840 $\mathrm{cm}^{-1}$ indicating the presence of $>\mathrm{C}=\mathrm{N}$ - and $-\mathrm{CH}=\mathrm{C}<$ linkage respectively. The result of this reaction is similar to what has been reported in case of reaction of malononitrile with benzalaniline ${ }^{1}$.

Treatment of 4-fluorobenzalaniline with ethyl cyanoacetate resulted in the formation of a crude solid which was recrystallized from benzene. The product was identified as ethyl 4-fluorobenzalcyanoacetate (3a), an addition-elimination product, with the help of elemental analysis and m.m.p. determination (no depression) with an authentic sample. This structure assignment for $\mathbf{3 a}$ was further confirmed on the basis of IR and PMR studies. The infrared spectrum contained absorption bands at 2230 and $1725 \mathrm{~cm}^{-1}$ indicating the presence of cyano and ester group respectively. The absorption at 1590 and 850 $\mathrm{cm}^{-1}$ showed the presence of $-\mathrm{CH}=\mathrm{C}<$ linkage. The PMR spectrum of $3 \mathrm{a}$ in $\mathrm{CDCl}_{3}$ has indicated ethyl protons of the ester group as a two proton quartet at $\delta 4.4$ and a three proton triplet at $\delta 1.5$ and four aromatic protons alongwith one olefinic proton as a multiplet between $\delta$ 6.9-8.3. The result of this reaction is at variance in comparison to such a study with benzalaniline where two products viz. $\alpha$-cyano- $\beta$-anilinodihydrocinnamic acid, an addition product with hydrolysed ester group (10\%) and ethyl benzalcyanoacetate, an addition-elimination product $(77 \%)$ have been reported ${ }^{1}$.

When ethyl acetoacetate was allowed to react with 4- 
fluorobenzalaniline, a solid separated out. The solid after recrystallization from benzene was identified as ethyl 4fluorobenzalacetoacetate (4a) with the support of elemental analysis, m.m.p. determination and spectral studies. The infrared spectrum of the compound showed bands at 1720 and 1590 and $855 \mathrm{~cm}^{-1}$ indicating the presence of ester group and $-\mathrm{CH}=\mathrm{C}<$ linkage respectively. The PMR spectrum of $4 \mathrm{a}$ in $\mathrm{CDCl}_{3}$ has shown a five proton multiplet between $\delta$ 6.8-8.3 for four aromatic protons and one olefinic proton, a three proton singlet at $\delta 2.4$ for $\mathrm{CH}_{3}$ protons of acetyl group and a two proton quartet at $\delta \mathbf{4 . 5}$ along with a three proton triplet at $\delta 1.4$ for $\mathrm{C}_{2} \mathrm{H}_{5}$ proton of ester group.

The crude product obtained by the condensation of acetylacetone with 4-fluorobenzalaniline was recrystallized from benzene. The compound was identified as 4fluorobenzalacetylacetone (5a) on the basis of elemental analysis, IR and PMR studies. The infrared spectrum of the compound indicated absorption bands at 1740 and 1590 and $860 \mathrm{~cm}^{-1}$ which were assigned to carbonyl group and $-\mathrm{CH}=\mathrm{C}<$ linkage respectively. In the PMR spectrum of $5 \mathrm{a}$ in $\mathrm{CDCl}_{3}$, the six proton singlet at $\delta 2.5$ was assigned to methyl protons of acetyl groups and the five proton multiplet between $\delta 6.9-8.3$ was due to four aromatic protons and one olefinic proton. The structure was further confirmed with the support of m.m.p. determination (no depression) with the authentic sample of the compound prepared by an alternative route. The result of this study is different from that of benzalaniline where an addition product has been reported.

The condensation of nitromethane with 4-fluorobenzalaniline yielded a crude solid which was recrystallized from benzene. The product was characterized as 4fluorobenzalnitromethane (6a), an addition-elimination product with the support of elemental analysis, m.m.p. determination (no depression) with authentic sample ${ }^{2}$ and IR studies. The infrared spectrum of the compound contained absorption bands at 990,1540 and $1360 \mathrm{~cm}^{-1}$ indicating the presence of $-\mathrm{CH}=\mathrm{C}<$ linkage and nitro group respectively.

The presence of fluoro substituent in the para position of C-phenyl ring of benzalaniline it seems, facilitates the formation of addition-elimination products rather than addition products. The carbanion formed from the active methylene compounds adds to the carbon-nitrogen double bond of 4-fluorobenzalaniline to give unstable addition product which loses the aniline molecule to yield stable addition-elimination product (Scheme 1). The 4fluorobenzal derivatives alongwith their characteristics are recorded in Table 1.

The 4-fluorobenzal derivatives 1a-6a were screened in vitro for their antifungal potential against Alternaria alternata, Fusarium oxysporum, Colletotrichum capsici and Myrothecium roridum by spore germination inhibition method at various concentrations. The results have been expressed in terms of $\mathrm{ED}_{50}$ values in Table 2 .

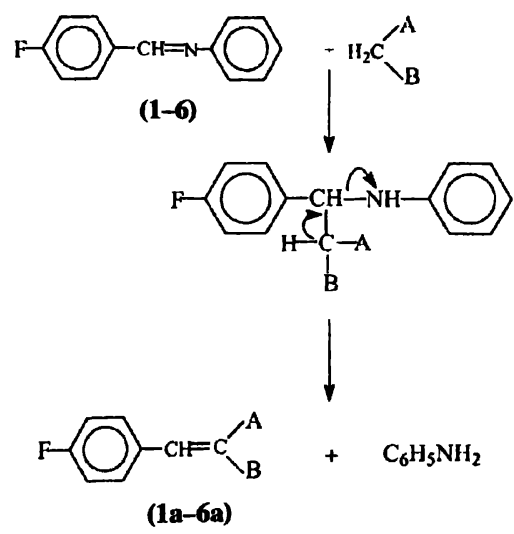

Scheme 1

Table 1. Characteristics of 4-fluorobenzal derivatives

\begin{tabular}{|c|c|c|c|c|c|}
\hline Compd. & $A$ & $B$ & $\begin{array}{l}\text { M.p. }{ }^{a} \\
\left({ }^{\circ} \mathrm{C}\right)\end{array}$ & $\begin{array}{l}\text { Yield } \\
(\%)\end{array}$ & $\begin{array}{l}\text { Molecular } \\
\text { formula }^{b}\end{array}$ \\
\hline $1 \mathbf{a}$ & $\mathrm{CN}$ & $\mathrm{COOH}$ & 104 & 38 & $\mathrm{C}_{10} \mathrm{H}_{6} \mathrm{O}_{2} \mathrm{NF}$ \\
\hline $2 \mathbf{a}$ & $\mathrm{CN}$ & $\mathrm{CN}$ & 130 & 40 & $\mathrm{C}_{10} \mathrm{H}_{5} \mathrm{~N}_{2} \mathrm{~F}$ \\
\hline 3a & CN & $\mathrm{COOC}_{2} \mathrm{H}_{5}$ & 88 & 35 & $\mathrm{C}_{12} \mathrm{H}_{10} \mathrm{O}_{2} \mathrm{NF}$ \\
\hline $4 a$ & $\mathrm{COCH}_{3}$ & $\mathrm{COOC}_{2} \mathrm{H}_{5}$ & 132 & 30 & $\mathrm{C}_{13} \mathrm{H}_{13} \mathrm{O}_{3} \mathrm{~F}$ \\
\hline $5 \mathbf{a}$ & $\mathrm{COCH}_{3}$ & $\mathrm{COCH}_{3}$ & 70 & 40 & $\mathrm{C}_{12} \mathrm{H}_{11} \mathrm{O}_{2} \mathrm{~F}$ \\
\hline $6 a$ & H & $\mathrm{NO}_{2}$ & 61 & 42 & $\mathrm{C}_{8} \mathrm{H}_{6} \mathrm{NO}_{2} \mathrm{~F}$ \\
\hline
\end{tabular}


Sandhar et al. : Reaction of active methylene compounds with 4-fluorobenzalanilines etc.

Table 2. Antufungal potential of 4-fluorobenzal derivatives

\begin{tabular}{lcccc} 
Compd. & \multicolumn{4}{c}{$\mathrm{ED}_{50}$ values (ppm) against } \\
\cline { 2 - 5 } 1a & A. alternata & F. oxysporum & C. capsici & M. roridum \\
2a & 750 & 690 & 310 & $*$ \\
3a & $*$ & $*$ & $*$ & $*$ \\
4a & $*$ & $*$ & 360 & 160 \\
5a & $*$ & 830 & $*$ & 85 \\
6a & $*$ & $*$ & $*$ & $*$ \\
Dithane M-45 & 30 & 910 & $*$ & $*$ \\
Bavistin & - & - & 12 & 32 \\
* More than $1000 \mathrm{ppm}$. & & - & - \\
\hline
\end{tabular}

Two of the compounds (2a and $5 \mathrm{a}$ ) have $\mathrm{ED}_{50}$ values more than $1000 \mathrm{ppm}$ against all the test fungi. Three compounds (1a. 4a and 6a) have $\mathrm{ED}_{50}$ values less than 1000 ppm against $F$. oxysporum. Two compounds $1 \mathrm{a}$ and 3a have better antifungal potential against $C$. capsici with $\mathrm{ED}_{50}$ value of 310 and $360 \mathrm{ppm}$. Ethyl 4-fluorobenzalacetoacetate (4a) has been found to possess promising antifungal potential against $M$. roridum and $A$. alternata with $\mathrm{ED}_{50}$ value of $85 \mathrm{ppm}$ and $140 \mathrm{ppm}$ respectively. The compound 3a namely ethyl 4-fluorobenzalcyanoacetate also possesses promising activity against $M$. roridum with $\mathrm{ED}_{50}$ value of $160 \mathrm{ppm}$.

\section{Experimental}

Reaction of active methylene compounds with 4fluorobenzalaniline :

4-Fluorobenzalaniline $(0.01 \mathrm{~mol})$ was dissolved in benzene $(20 \mathrm{ml})$ in a conical flask $(100 \mathrm{ml})$. Active methylene compound $(0.01 \mathrm{~mol})$ was added to the above solution. Then a few drops of pyridine were added. The mixture was warmed with stirring, cooled, stoppered and allowed to stand at room temperature overnight when a crude solid separated out. The crude product was filtered and recrystaiiized from suitable solvent to get respective 4-fluorobenzal derivative (1a-6a).

\section{In vitro screening for antifungal potential :}

The stock solution of each compound was prepared by dissolving each chemical $(20 \mathrm{mg})$ in absolute alcohol $(0.5 \mathrm{ml})$ and the volume was made to $10 \mathrm{ml}$ by adding sterilized distilled water. The stock solution of $2000 \mathrm{ppm}$ of each compound, thus, prepared on active ingredient basis was kept in refrigerator till further use. The required dilutions of $1000,500,250,100$ and $50 \mathrm{ppm}$ were subsequently made from the stock solution by adding sterilized distilled water as and when required.

Small droplets $(0.02 \mathrm{ml})$ of test solution and spore suspension in equal amount were seeded in the cavity slides. These slides were kept in petriplates lined with moist filter paper and then incubated for $24 \mathrm{~h}$ at $25 \pm 1$ ${ }^{\circ} \mathrm{C}$. The slides were checked for percent germination occurred and percent spore germination inhibition was calculated and $\mathrm{ED}_{50}$ values were determined.

\section{References}

1. M. R. Manrao, Chander Kanta, R. C. Sharma and P. S. Kalsi, J. Indian Council Chem., 1995, 11, 35; M. R. Manrao, P. Kaur, K. K. Gill, R. C. Sharma and P. S. Kalsi, J. Indian Council Chem., 1995, 11, 63; R. K. Sandhar, J. R. Sharma and M. R. Manrao, J. Indian Council Chem., 2004, 21. 8; M. R. Manrao and V. K. Kaul, Indian J. Agric. Chem., 1999, 32, 33; R. K. Sandhar, M. R. Manrao and V. K. Kaul, Indian J. Nematol., 2003, 33, 193.

2. R. K. Sandhar, J. R. Sharma and M. R. Manrao, Pestic. Res. J., 2003, 15, 129. 